\title{
Fitting Volume Models for Parana Pine With a Nonlinear Regression, Genetic Algorithm and Simulated Annealing
}

\author{
Emanuel Arnoni Costa ${ }^{1}$, Cristine Tagliapietra Schons ${ }^{1}$, César Augusto Guimarães Finger ${ }^{1} \&$ André Felipe Hess ${ }^{2}$ \\ ${ }^{1}$ Forest Science, Federal University of Santa Maria, Brazil \\ ${ }^{2}$ Forest Science, State University of Santa Catarina, Brazil \\ Correspondece: Emanuel Arnoni Costa, Forest Science, Federal University of Santa Maria, Brazil. E-mail: \\ emanuelarnonicost@hotmail.com
}

Received: December 7, 2021

Accepted: January 4, 2022

Online Published: January 15, 2022

doi:10.5539/jas.v14n2p36

URL: https://doi.org/10.5539/jas.v14n2p36

\begin{abstract}
Improving volumetric quantification of Parana pine (Araucaria angustifolia) in Mixed Ombrophilous Forest is a constant need in order to provide accurate and timely information on current and future growing stock to ensure forest management. Thus, the present study aimed to evaluate and compare the volume estimates obtained through Nonlinear Regression (NR), Genetic Algorithm (GA) and Simulated Annealing (SA) in order to generate accurate volume estimates. Volumetric equations were developed including the independent variables diameter at breast height (dbh), total height (h) and crown rate (cr) and from the fit through the NR, GA and SA approaches. The GA and SA approaches evaluated proved to be a reliable optimization strategy for parameter estimation in Parana pine volumetric modelling, however, no significant differences were found in comparison with the NR approach. This study therefore contributes through the generation of robust equations that could be used for accurate estimates of the volume of the Parana pine in southern Brazil, thus supporting the planning and establishment of management and conservation actions.
\end{abstract}

Keywords: Metaheuristic algorithms, parameter estimation, araucaria, optimization methods

\section{Introduction}

Timber valuation is a prime requirement to ensure forest management. In this regard, forest managers constantly resort to estimating forest attributes in order to provide accurate and timely information on current and future growing stock and to assess the economic benefits of their forests, not only at large scale industrial forests but also at small scale forests (Tiryana et al., 2021). Therefore, the development of accurate prediction tools is crucial to support forest management decisions, which have to be adapted to suit the particular circumstances (Özçelik et al., 2010).

Parana pine (Araucaria angustifolia), a characteristic species of the Mixed Ombrophilous Forest (MOF) of the Atlantic Forest biome, is an important coniferous species in southern Brazil of considerable economic importance due to its exceptional wood quality and its high-value edible seeds (Hess et al., 2019, Costa et al., 2020). The species' trunk is highly cylindrical, straight and, rarely, branched into two or more shafts, its bark is thick and resinous, and it also has a unique crown structure (Narvaes et al., 2005; Rodrigues, 2016). In the early 1900 s, it is estimated that this species covered approximately $200,000 \mathrm{~km}^{2}$ in the south of the country (Hueck 1972).

Due to unsustainable logging and agricultural expansion in past decades, MOF typology have experienced a significant reduction in its original area, culminating in the development of legal barriers for the cutting of Parana pine (Eisfeld et al., 2020). However, several researches have pointed out that these restrictions has not been effective to improve the state of conservation of the species (IUCN, 2021), since the the lack of management in this typology has led to a great increase in competition between trees, impeding natural regeneration and stagnating growth (Beckert et al., 2014; Costa et al., 2020; Hess et al., 2020, 2018a, 2018b). Therefore, studies that contribute to the planning of sustainable forest management and conservation of this species are crucial.

Regression models are commonly used to model forest attributes. However, the fitting of nonlinear equations is more difficult than for linear models, since traditional regression methods for nonlinear models, in some cases, 
require initial parameter estimates to start the optimization and often the quality of the final solution is dependent upon the position of this starting point in the search space (Roush \& Branton, 2005). Another difficulty with nonlinear models fitting is determining if a given minimum is the best (global) minimum or a suboptimal (local) minimum (R. L. Haupt \& S. E. Haupt, 2004).

As an alternative to solve these problems, it is possible to resort to more robust optimization methods, such as metaheuristic algorithms approaches (Bonilla-Petriciolet et al., 2005). These methods present several advantages over traditional nonlinear regression (NR), such as the possibility of specifying only the range of the model parameters (Kapanoglu et al., 2007; Moreira et al., 2013). In addition, metaheuristic approaches are more appropriate to deal with ill-conditioned optimization problems than is nonlinear regression (Hadi \& Gonzalez-Andujar, 2009).

In this regard, genetic algorithm (GA) is a computational method modeled on the theory of biological evolutionary processes that can be used to find optimal solutions (Roush \& Branton 2005). The success of the algorithm is attributed to various factors including its powerful parallel search capability, computational simplicity, robustness and focus on global rather than local search space (Hadi \& Gonzalez-Andujar, 2009; Pohjankukka et al., 2018; Zeng et al., 2007). Simulated annealing (SA) is another notable heuristic approach based on neighborhood search technique (Dong et al., 2015). It has analogy with annealing of a metal from which the name comes and the central idea of the method is to avoid local optima by accepting probabilistically moves to worse solutions (Packalén et al., 2012).

Thus, the present study expected to contribute to the increase of information on the volumetry of the Araucaria angustifolia in southern Brazil, with the objective of evaluating and comparing the volume estimates obtained through Nonlinear Regression (NR), Genetic Algorithm (GA) and Simulated Annealing (SA).

\section{Material and Methods}

\subsection{Study Site}

The data were collected in an 84-hectare uneven-aged natural forest located in the municipality of Lages, SC $\left(27^{\circ} 48^{\prime} \mathrm{S} ; 50^{\circ} 19^{\prime} \mathrm{W}\right)$. The region's climate is mesothermic humid $(1,360$ to $1,600 \mathrm{~mm})$, with no defined dry season $(\mathrm{Cfb})$, with an average annual temperature between 13.8 and $15.8{ }^{\circ} \mathrm{C}$ and a relative humidity of $80 \%$ (Alvares et al., 2013). The predominant soils in the region are humic nitosols and humic cambisols developed from basaltic rocks.

\subsection{Data Collection}

A total of 308 araucaria trees were selected in the forest by an entirely random sampling process within diameter classes (see the relative sampling error in the Table 1), covering the range of diametric distribution previously established by (Hess et al., 2010). In each tree were measured: the diameter at breast height (dbh) with a diametric tape; the total height (h) and the crown insertion height (hic) with a Vertex IV hypsometer. To obtain the diameters along the trunk, Hohenadl's rigorous cubing method was considered with the relative diameters $\left(\mathrm{d}_{\mathrm{i}}\right)$ measured at specific heights $\left(\mathrm{h}_{\mathrm{i}}\right)$ of $10 \%, 30 \%, 50 \%, 70 \%$ of the $\mathrm{h}$, as well as the diameter at the crown insertion $\left(\mathrm{d}_{\mathrm{ic}}\right)$, thus allowing the determination of the commercial volume $(\mathrm{v})$ of the trees.

To determine the $d_{i}$ and $h_{i}$ values, the electronic dendrometer Criterion RD 1000 by laser technology ${ }^{\circledR}$ was used, which allowed the cubing of standing trees. In this case, the destructive method was not applied due to the restrictive legislation for cutting trees of this species, even for research purposes. The diameter at $90 \%$ of the height was not considered because it is located inside the canopy and the presence of branches hinder its determination in the forest.

The crown rate (cr) was obtained considering the ratio between the crown length $(\mathrm{cl})$ and the total height $(\mathrm{h})$. The cl was calculed by the difference between the total height (h) and the height at the crown insertion (hic) of the tree. The characteristics of the trees evaluated are shown in Table 1. 
Table 1. Characteristics of measured trees

\begin{tabular}{llllllll}
\hline Variables & Unit & Minimun & Mean & Median & Maximum & S.D. & Rse $\%$ \\
\hline $\mathrm{dbh}$ & $\mathrm{cm}$ & 9.8 & 37.8 & 37.2 & 86.0 & 15.7 & 4.66 \\
$\mathrm{~h}$ & $\mathrm{~m}$ & 7.2 & 16.6 & 16.7 & 25.0 & 3.6 & 2.43 \\
$\mathrm{hic}$ & $\mathrm{m}$ & 3.0 & 12.1 & 12.8 & 19.0 & 3.7 & 3.43 \\
$\mathrm{~h} / \mathrm{dbh}$ & $\%$ & 24.1 & 48.8 & 45.9 & 102.4 & 14.8 & 3.40 \\
$\mathrm{cr}$ & $\%$ & 5.1 & 28.2 & 25.3 & 75.0 & 13.3 & 5.29 \\
$\mathrm{v}$ & $\mathrm{m}^{3}$ & 0.0248 & 1.2118 & 0.8589 & 6.2624 & 1.1815 & 10.93 \\
\hline
\end{tabular}

Note. $\mathrm{dbh}=$ diameter at breast height $(\mathrm{cm}) ; \mathrm{h}=$ total height $(\mathrm{m}) ;$ hic $=$ crown insertion height; $\mathrm{h} / \mathrm{d}=$ ratio between height and diameter $(\%) ; \mathrm{cr}=$ crown rate $(\%) ; \mathrm{v}=$ tree commercial volume $\left(\mathrm{m}^{3}\right) ;$ S.D. $=$ standard deviation; Rse $=$ relative sampling error $(\%)$.

The nonlinear trend between the volume variable (v) and the diameter variable (dbh) can be seen through (Figure 1).

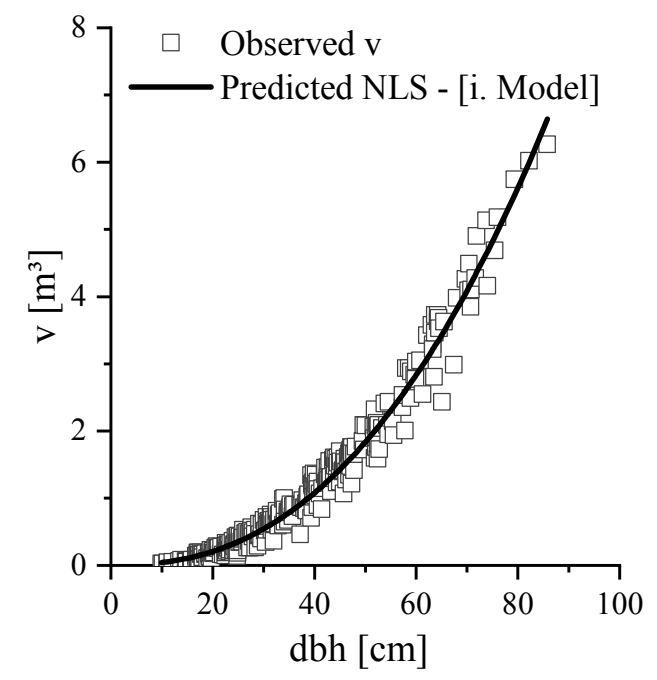

Figure 1. Dispersion of volume data as a function of dbh

\subsection{Volume Modeling}

The following volumetric models (i, ii and iii) were selected to be fitted through Nonlinear Regression, Genetic Algorithm and Simulated Annealing methods.

$$
\begin{gathered}
v=\beta_{0} d b h^{\beta_{1}} \\
v=\beta_{0} d b h^{\beta_{1}} h^{\beta_{2}} \\
v=\beta_{0} d b h^{\beta_{1}} h^{\beta_{2}} c r^{\beta_{3}}
\end{gathered}
$$

Where, $v=$ estimated tree volume $\left(\mathrm{m}^{3}\right) ; d b h=$ diameter at breast height $(\mathrm{cm}) ; h=$ total height $(\mathrm{m}) ; c r=$ crown rate $(\%) ; \beta_{0} ; \beta_{1} ; \beta_{2} ; \beta_{3}=$ parameters to be estimated.

The fitting of the models through nonlinear regression was performed using the Gauss-Newton algorithm. For the optimization through Genetic Algorithm, the R package ' $G A$ ' was used, setting the following parameters: population size $=2500$; maximum number of iterations $=50,000$; crossover probability $=0.8$; mutation probability $=0.1$. For the Simulating Annealing implementation, the R package 'likelihood' was used and the following parameters were assumed: initial temperature $=3$; cooling rate $=0.95$; maximum number of iterations $=50,000$.

Both GA \& SA have the advantages of defining only a range of the equation parameters in the search space (R. L. Haupt \& S. E. Haupt, 2004), which is not possible in the case of nonlinear regression in some specific programs that require starting points. Table 2 shows the start values for the fitting of each method. 
Table 2. Starting points for nonlinear regression and parameter ranges for genetic algorithm and simulated annealing fitting

\begin{tabular}{|c|c|c|c|c|c|}
\hline Type & Models & $\beta_{0}$ & $\beta_{1}$ & $\beta_{2}$ & $\beta_{3}$ \\
\hline \multirow{3}{*}{ NLS } & $\mathrm{i}$ & 0.0001 & 2.25 & & \\
\hline & ii & 0.0001 & 2.25 & 0.75 & \\
\hline & iii & 0.0001 & 2.25 & 0.75 & -0.25 \\
\hline \multirow{3}{*}{ GA } & $\mathrm{i}$ & $0-2$ & $2-3$ & & \\
\hline & ii & $0-2$ & $2-3$ & $0.5-1$ & \\
\hline & iii & $0-2$ & $2-3$ & $0.5-1$ & $-0.5-0$ \\
\hline \multirow{3}{*}{ SA } & $\mathrm{i}^{-}$ & $0-1$ & $2-3$ & & \\
\hline & ii & $0-1$ & $2-3$ & $0.5-1$ & \\
\hline & iii & $0-1$ & $2-3$ & $0.5-1$ & $-0.5-0$ \\
\hline
\end{tabular}

Note. $\mathrm{NLS}=$ nonlinear regression; $\mathrm{GA}=$ genetic algorithm and $\mathrm{SA}=$ simulated annealing.

\subsection{Relationships of Variables}

The adjustment of the models of $h$ and $c r$ were possible by the following expressions:

$$
\begin{gathered}
h=\beta_{0} \exp \left(\frac{-\beta_{1}}{d b h}\right) \\
c r=\beta_{0} d b h^{\beta_{1}}
\end{gathered}
$$

Where, $h=$ total height $(\mathrm{m}) ; c r=$ crown rate $(\%) ; d b h=$ diameter at breast height $(\mathrm{cm}) ; \beta_{0} ; \beta_{1}=$ parameters to be estimated.

The relationship between the variables $(v, d b h, h$ and $c r)$ were analyzed using the three-dimensional representation with the response surface.

\subsection{Statistical Analysis}

In the evaluation of the models generated by the different approaches, we considered as goodness-of-fit criteria the root mean square error (RMSE) (Expression vi), the Bias (B) (Expression vii), the Akaike's information criterion (AIC) (Expression viii) and the graphical analysis of the residuals.

$$
\begin{gathered}
R M S E=\sqrt{\left[\frac{\sum_{i=1}^{n}\left(y_{i}-\hat{y}_{i}\right)^{2}}{n}\right]} \\
B=\frac{\sum_{i=1}^{n}\left(y_{i}-\hat{y}\right)}{n} \\
A I C=n \cdot \ln \left[\frac{\sum_{i=1}^{n}\left(y_{i}-\hat{y}_{i}\right)^{2}}{n}\right]+2 k
\end{gathered}
$$

Where, $R M S E=$ root mean square error; $B=$ Bias; $A I C=$ Akaike's information criterion; $y_{i}=$ observed value for the $i^{\text {th }}$ observation; $\hat{y}_{i}=$ predicted value for the $i^{\text {th }}$ observation; $n=$ number of observations in the dataset; $k=$ number of parameters.

To verify significant differences among the different fitting approaches, was tested the equality of variances, the $\mathrm{F}$ test was applied at the 5\% level of significance. The non-linear extra sum of squares method was used to compare the models (i, ii and iii) (Bates \& Watts, 1988). In this method, the fitting of full and reduced models is required. The significance of the comparison between full and reduced models is based on the F-test, according to the following expression:

$$
F=\frac{\frac{\left(s_{S E R}-s_{S E F}\right)}{\left(d_{f R}-d_{f F}\right)}}{\frac{S_{S E F}}{d_{f F}}}
$$

Where, $S_{S E R}=$ is the sum square error of the reduced model; $S_{S E F}=$ is the sum square error of the full model; $d_{f R}$ $=$ is the degrees of freedom for the reduced model; $d_{f F}=$ and is the degrees of freedom for the full model. The non-linear extra sum of squares follows an F-distribution. F-test was considered significant if the Pr-value for the test is less than 0.05 . All the statistical analyses were processed using software R 3.4.4. 


\section{Results}

The sample trees covered a wide range of diameter $(9.8-86.0 \mathrm{~cm})$ and height $(7.2-25.0)$. In addition, from very large crown trees to trees with shorter crowns were included in the sample (5.1-75.0\%). On average, the trees volume was $1.2118 \mathrm{~m}^{3}$ (Table 1 and Figure 1). Relative sampling error values were below or very close to $10 \%$ for all evaluated variables.

The coefficients fitted through NR, GA and SA, followed by their respective values RMSE, B and AIC, are presented in the Table 3, considering each based volumetric model. First, considering only the different models used, a gain in precision was observed with the inclusion of the height variable (h) in relation to only the diameter (dbh) [NLS-ii. Model]. Likewise, the inclusion of the crown rate variable (cr) brings an important contribution, with reduction in the RMSE, B and AIC. Thus, regardless of the fitting approach, [NLS-iii. Model] showed better performance among those evaluated for the volumetric estimates. All the coefficients of the equations fitted presented significance ( $\operatorname{Pr}<0.0001$, see Appendix A). Significant differences observed between models (i and ii; i and iii; ii and iii) based on the F-test using the non-linear extra sum of squares method, which allows the comparison between equations with different amount of coefficients, corroborate with the precision statistics and confirm the superiority of the model iii (Appendix B). Negative values for the $b_{3}$ coefficient were found due to the fact that a reduction in the percentage of crown rate reflects an increase in volume.

Table 3. Coefficients and statistics of the adjusted equations for volume estimation

\begin{tabular}{lllllllll}
\hline Type & Models & $\mathrm{b}_{0}$ & $\mathrm{~b}_{1}$ & $\mathrm{~b}_{2}$ & $\mathrm{~b}_{3}$ & RMSE & $\mathrm{B}$ & $\mathrm{AIC}$ \\
\hline \multirow{3}{*}{$\mathrm{NLS}$} & i & 0.000164 & 2.3835 & & & 0.1783 & -0.0031 & -1058.3 \\
& ii & 0.000053 & 2.1290 & 0.7267 & & 0.1248 & -0.0031 & -1276.1 \\
& iii & 0.000075 & 2.1400 & 0.8114 & -0.2042 & 0.0440 & -0.0006 & -1916.7 \\
\hline \multirow{3}{*}{$\mathrm{GA}$} & i & 0.000165 & 2.3819 & & & 0.1783 & -0.0035 & -1058.3 \\
& ii & 0.000049 & 2.1441 & 0.7311 & & 0.1250 & -0.0016 & -1274.9 \\
& iii & 0.000076 & 2.1402 & 0.8109 & -0.2041 & 0.0440 & -0.0006 & -1916.7 \\
\hline \multirow{3}{*}{$\mathrm{SA}$} & i & 0.000164 & 2.3835 & & & 0.1783 & -0.0031 & -1058.3 \\
& ii & 0.000053 & 2.1290 & 0.7268 & & 0.1248 & -0.0031 & -1276.1 \\
& iii & 0.000075 & 2.1400 & 0.8116 & -0.2043 & 0.0440 & -0.0006 & -1916.7 \\
\hline
\end{tabular}

Note. NLS $=$ nonlinear regression; $\mathrm{GA}=$ genetic algorithm and $\mathrm{SA}=$ simulated annealing.

Additionally, regarding to the different fitting approaches, small differences in the adjusted values of the parameters were observed among nonlinear regression, genetic algorithm and simulated annealing (Table 3), resulting in very similar precision statistics. The comparative $\mathrm{F}$ test between the different volumetric estimation approaches proved that there was no significant difference between the approaches, at the $5 \%$ level of significance (Table 4).

Table 4. Statistical results for comparing residuals the different volumetric estimation approaches

\begin{tabular}{lclll}
\hline Comparing & Models & df & F value & p-value \\
\hline NLS-GA & & 307 & 1.0007 & 0.9954 \\
NLS-AS & i & 307 & 1.0001 & 0.9995 \\
GA-AS & & 307 & 1.0006 & 0.9958 \\
\hline NLS-GA & 307 & 1.0441 & 0.7058 \\
NLS-AS & ii & 307 & 1.0002 & 0.9989 \\
GA-AS & & 307 & 1.0439 & 0.7069 \\
\hline NLS-GA & & 307 & 1.0008 & 0.9947 \\
NLS-AS & iii & 307 & 1.0007 & 0.9952 \\
GA-AS & & 307 & 1.0014 & 0.9899 \\
\hline
\end{tabular}

Note. $\mathrm{NLS}=$ nonlinear regression; $\mathrm{GA}=$ genetic algorithm and $\mathrm{SA}=$ simulated annealing. 
Therefore, considering the non-significant differences observed between the different approaches, for the data set and the models assessed in this study, it can be observed that non-linear regression proved to be a suitable approach for adjusting the variable volume as other approaches. Consequently, taking into account the simplicity, in this study we chose to select the non-linear regression approach for the application.

The box plots in Figure 2 illustrate the residual distributions of each model evaluated through nonlinear regression. Residual dispersion presents a shorter range and a small interquartile difference, especially regarding [NLS-iii. Model] (Figure 2), which also showed mean and median values centered close to zero.

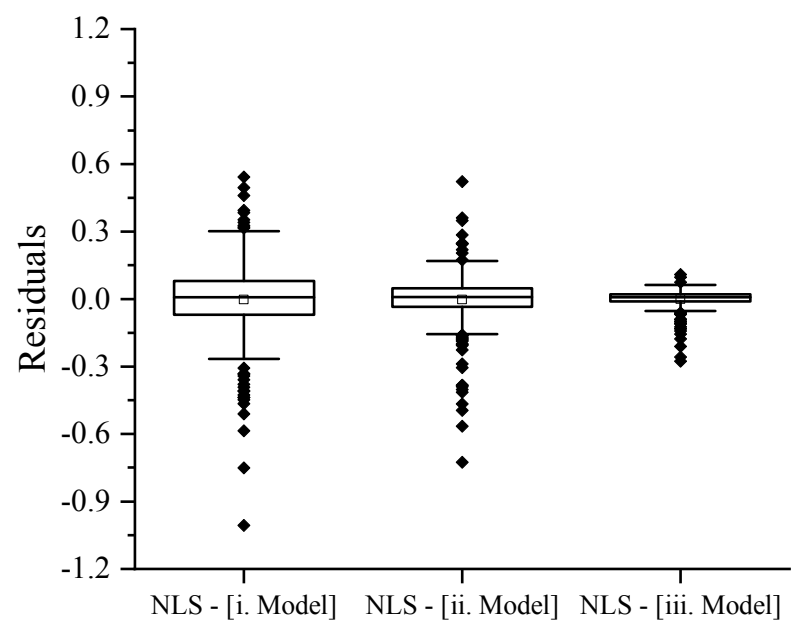

Figure 2. Residual analysis of the each model fit through the nonlinear regression approach

After confirming the best performance of [NLS-iii. Model] in predicting the volume variable, we then proceeded with the adjustment of the variables h [NLS-iv. Model] and cr [NLS-v. Model] according to the dbh. The fitted coefficients and the goodness-of-fit criteria RMSE, B and AIC are presented in the Table 5.

Table 5. Coefficients and statistics of the adjusted equations for $\mathrm{h}$ and cr estimation according to the dbh variable

\begin{tabular}{lllllll}
\hline Models & Variables & $\mathrm{b}_{0}$ & $\mathrm{~b}_{1}$ & RMSE & $\mathrm{B}$ & AIC \\
\hline iv & $\mathrm{h}$ & 24.1732 & 12.3517 & 2.2988 & $5.27 \mathrm{E}-03$ & 516.7 \\
v & $\mathrm{cr}$ & 69.9343 & -0.2583 & 12.9106 & $1.52 \mathrm{E}-02$ & 1579.8
\end{tabular}

The trend of height (h) and crown rate (cr) as a function of the diameter (dbh) can be seen through (Figure 3$)$. 

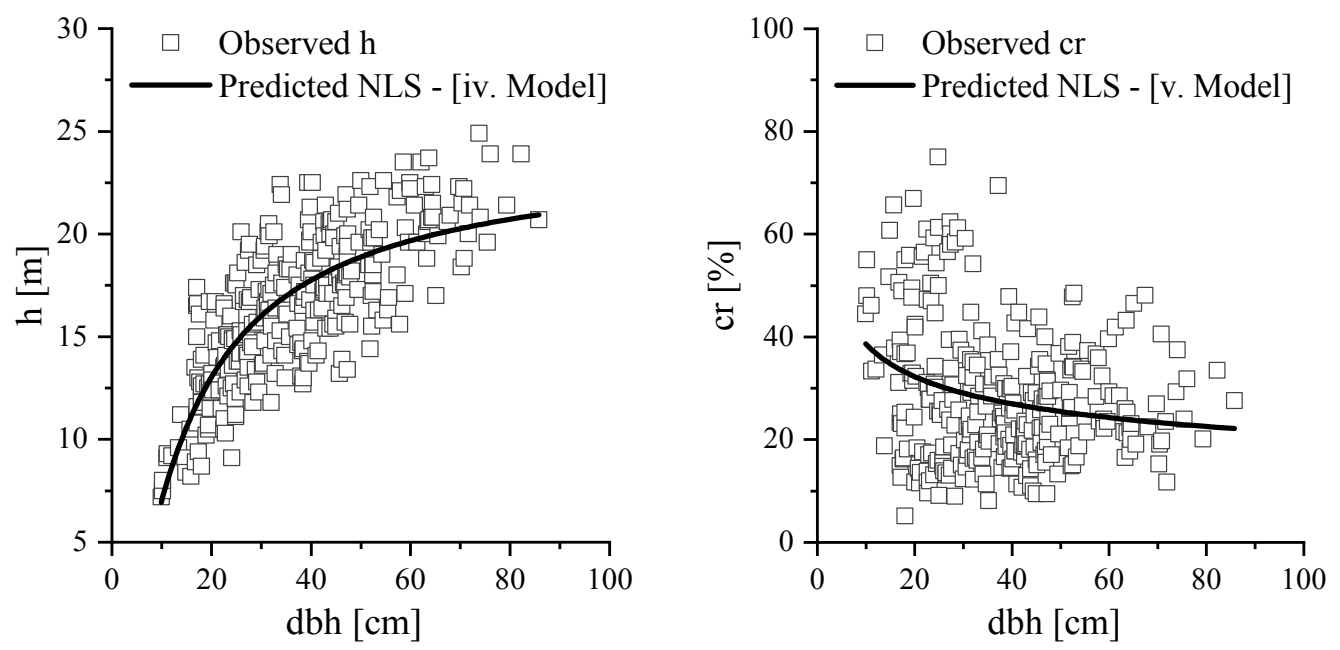

Figure 3. Dispersion data of height (h) and crown rate (cr) as a function of the diameter at breast height (dbh)

The three-dimensional volume data is shown in Figure 4a. Additionally, the relation among the independent variables $\mathrm{cr}$, dbh and $\mathrm{h}$ can also be seen in Figure 4b. The generated equation (NLS-iii. Model) is the main result of the present study, which represents accurate volumetric estimates for individual trees of Araucaria angustifolia.

\section{Discussion}

This study investigates different approaches in adjusting volume models for the species Araucaria angustifolia in uneven-aged forest in southern Brazil, introducing new possibilities for parameter optimization through genetic algorithm and simulated annealing. Valuable contribution are delivered in the scope of improving volumetric estimates for the Brazilian pine species, covering in its sample trees in a wide diametric range, by including individuals from approximately $10 \mathrm{~cm}$ dbh to almost $90 \mathrm{~cm}$ (Table 1), which characterize the formations most commonly seen in southern Brazil.

The non-significant difference observed in the present study between the regression and metaheuristic algorithm approaches (Table 4) may have been verified due to the fact that we are working with simple models and with a maximum of three variables (Expression i, ii and iii). In this context, when ill-conditioned optimization is not an issue and the definition of the starting points' values are reasonable, the simplest method could be used to estimate the volume of Parana pine in southern Brazil, obtaining a good performance with the use of nonlinear regression (see Table 3-lower values of RMSE, bias and AIC).

It is to be expected, however, that for more complex problems, these metaheuristics alternatives can become quite viable. In this sense, given the advantages they can present, we point out to the importance of additional investigations related to these approaches in the context of forest attributes estimates, as they are still very scarce.

Some other authors have based studies with the application of metaheuristic approaches in the forest context, but in particular with the approach of selecting variables for the composition of the models (feature selection). Garcia-Gutierrez et al. (2014) compare the results of two classical procedures (stepwise and best-subset) and a novel GA regression procedure for the selection of variables when multiple linear regression is applied on LiDAR data for the estimation of the main forest stand variables. The results indicated that GAs statistically outperformed the rest of the methods and the authors suggested that the parametric conditions in field data could be the main reason for the better performance of GA. 

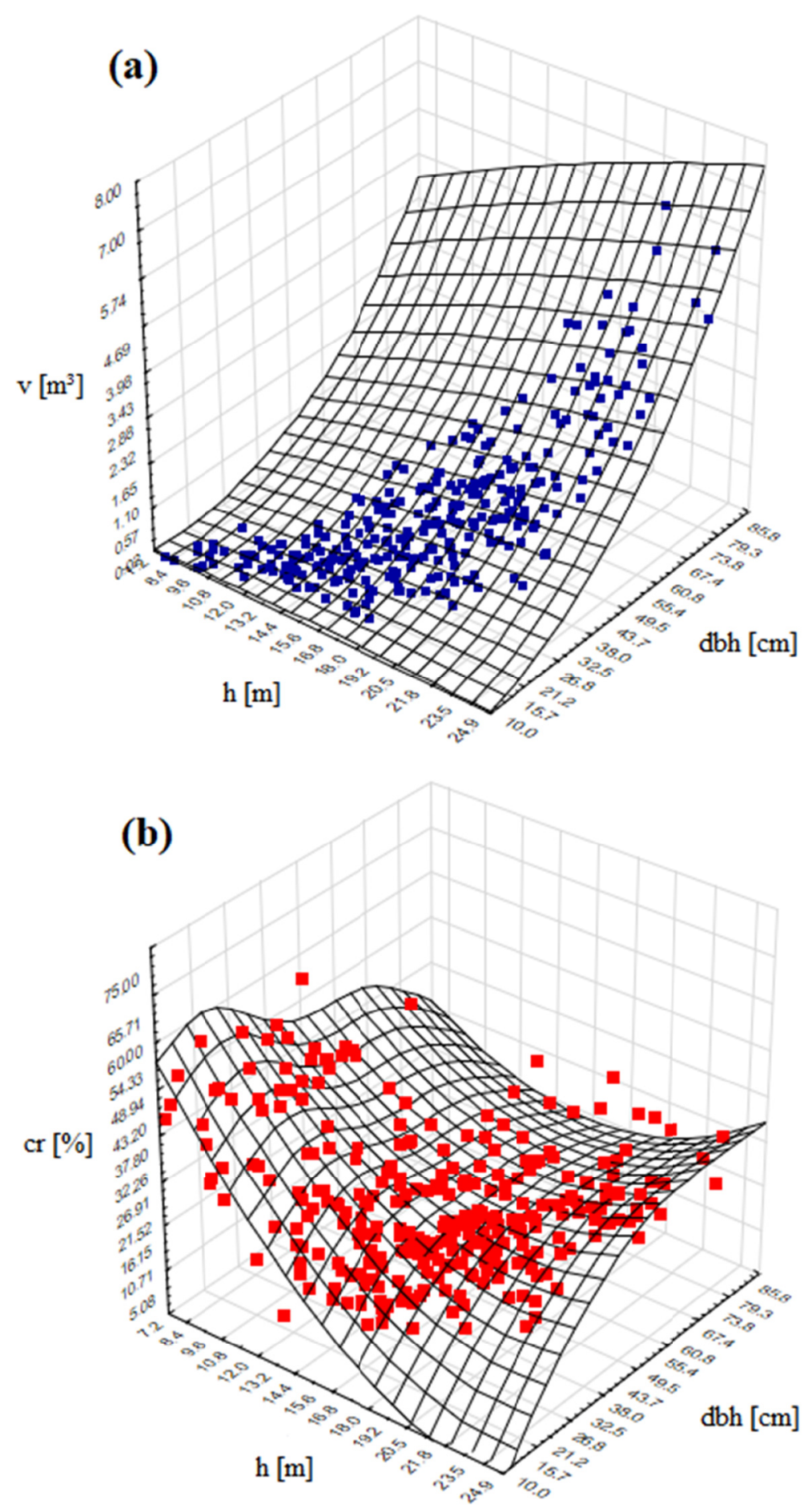

Figure 4. Response surface of the volume as a function of $\mathrm{dbh}$ and $\mathrm{h}(\mathrm{a})$; and of the cr as a function of dbh and $h(b)$

In the context of vegetation classification with hyperspectral data, Li et al. (2019) also compared feature selection methods, including genetic algorithm, simulated annealing, stepwise discriminant analysis and recursive feature elimination. The authors concluded that, for the evaluated case, the four methods assessed generate almost the same classification accuracy. Genetic algorithm optimization also have extended application in the context of feature selection for estimation of forest biomass (Guerra-Hernández et al., 2016; Pham et al., 2020; Tuominen \& Haapanen, 2013) and carbon sequestration (Paul \& Roxburgh, 2020). 
In addition, genetic algorithms and simulated annealing also have their consolidated use in the context of forest planning, at all levels: strategic, tactical, and operational (Sessions et al. 2007). For example, Dong et al. (2015) concentrated on tactical forest spatial harvest scheduling problems through the use of the simulated annealing algorithm. Similarly, Zeng et al. (2007) explored heuristic optimization in risk management of wind damage in forest planning, testing simulated annealing, genetic algorithms and tabu search. In this study, tabu search performed slightly better than simulated annealing and genetic algorithms, addressing another important optimization algorithm.

Specifically for the volumetric modeling of the Parana pine, other authors have also been trying to increase the reliability of the estimation tools for the species. Martins et al. (2017) tested the performance of artificial intelligence techniques to assess their contribution in the estimation of stem form of Araucaria angustifolia and identified that artificial neural networks provided the best estimates. Similarly, mixed nonlinear models fitting techniques were also evaluated by Costa (2014) to describe the taper of Parana pine stems, which showed flexibility and efficiency.

In the present study, the possibility of including the crown rate variable (cr) in the model proved to be of great contribution, representing gains in precision in the adjustments (Table 3, Appendices A and B), regardless of the approach considered (Table 4). Testing the contribution of crown variables to volume models is particularly relevant in a current context of forest inventory via remote imaging (Dalponte et al., 2014; Y. Li et al., 2017; Puliti et al., 2015, 2020). In this perspective, the combination of laser scanning technologies and the use of Unmanned Aerial Vehicles (UAV) have increasingly advanced in the direction of individual tree crowns identification and delineation (Guerra-Hernández et al., 2019; Puliti et al., 2020), therefore, the studied relationship between volume and crown variable represents a differential of the present study and a useful tool for future studies using UAV.

Furthermore, the volume determination obtained with a non-destructive method (Criterion RD1000) also proved to be feasible, allowing the sampling of $308 \mathrm{~A}$. angustifolia trees without felling. Indirect volume measurement have been used satisfactorily in other recent studies (de Oliveira et al., 2018; He et al., 2016; Marchi et al., 2020), proven to be a cheaper and desirable method. de Oliveira et al. (2018) reached non-significant differences between volumes determined by direct and indirect methods for Khaya ivorensis A. Chev. plantations in Brazil, assuring precision for indirect measurements. Rodriguez et al. (2014) also compared the volume estimations obtained with destructive methods against the volume estimation obtained with the electronic dendrometer Criterion RD1000 and the laser hypsometer TruPulse, for Pinus nigra Arn. and Pinus pinaster Ait. Mesogeensis trees. These authors highlight the need for measurements to always be taken from a distance approximately equal to the tree height, considering this as an "accurate position". For A. angustifolia, this alternative is especially important in the current context of cutting restrictions established by legislation, even for research purposes. In this way it was possible to take a robust sample, leading to reliable results.

Finally, we consider that the final application of this study is the delivery of robust volume equations, which covers a large data amplitude and with multiple-entry ( $\mathrm{dbh}, \mathrm{h}$ and $\mathrm{cr}$ ), that could be used for accurate estimates of the volume of the Parana pine in southern Brazil.

\section{Conclusion}

The genetic algorithm and simulated annealing approaches evaluated proved to be a reliable optimization strategy for parameter estimation in Parana pine volumetric modelling.

No significant differences were found between the volumes estimated by the different approaches, indicating that the simplest method, nonlinear regression, can be used to estimate the volume of Parana pine. In addition, the inclusion of the crown rate variable demonstrated a gain in model accuracy.

This study contributes by generating robust equations that could be used for accurate estimates of the volume of Parana pine, thus contributing to species management and conservation strategies.

\section{References}

Alvares, C. A., Stape, J. L., Sentelhas, P. C., De Moraes Gonçalves, J. L., \& Sparovek, G. (2013). Köppen's climate classification map for Brazil. Meteorologische Zeitschrift, 22(6), 711-728. https://doi.org/10.1127/ 0941-2948/2013/0507

Bates, D. M., \& Watts, D. G. (1988). Nonlinear Regression Analysis and Its Applications. John Wiley \& Sons.

Beckert, S. M., Rosot, M. A. D., \& Rosot, N. C. (2014). Crescimento e dinâmica de Araucaria angustifolia (Bert.) O. Ktze. em fragmento de Floresta Ombrófla Mista. Scientia Forestalis, 42(102), 209-218. 
Bonilla-Petriciolet, A., Lira-Padilla, M. G., \& Soto-Becerra, C. A. (2005). Aplicación del método de optimización de recocido simulado en la regresión de isotermas de adsorción. Revista Internacional de Contaminación Ambiental, 21(4), 201-206.

Costa, E. A. (2014). Modelo não linear misto para descrever o afilamento do tronco de Araucaria angustifolia no sul do Brasil. Universidade Federal de Santa Maria, Brazil.

Costa, E. A., Liesenberg, V., Hess, A. F., Finger, C. A. G., Schneider, P. R., Longhi, R. V., Schons, C. T., \& Borsoi, G. A. (2020). Simulating Araucaria angustifolia (Bertol.) Kuntze timber stockswith liocourt's law in a natural forest in southern Brazil. Forests, 11(3), 1-14. https://doi.org/10.3390/f11030339

Dalponte, M., Ørka, H. O., Ene, L. T., Gobakken, T., \& Næsset, E. (2014). Tree crown delineation and tree species classification in boreal forests using hyperspectral and ALS data. Remote Sensing of Environment, 140, 306-317. https://doi.org/10.1016/j.rse.2013.09.006

de Oliveira, X. M., Ribeiro, A., Ferraz Filho, A. C., Mayrinck, R. C., de Lima, R. R., \& Scolforo, J. R. S. (2018). Volume equations for Khaya Ivorensis A. Chev. plantations in Brazil. Anais Da Academia Brasileira de Ciencias, 90(4), 3285-3298. https://doi.org/10.1590/0001-3765201820170852

Dong, L., Bettinger, P., Liu, Z., \& Qin, H. (2015). A comparison of a neighborhood search technique for forest spatial harvest scheduling problems: A case study of the simulated annealing algorithm. Forest Ecology and Management, 356, 124-135. https://doi.org/10.1016/j.foreco.2015.07.026

Eidisffel, R. L., Arce, J. E., Sanquetta, C. R., \& Braz, E. M. (2020). Is it forbidden the wood use of Araucaria angustifolia? An analysis on the current legal budget. Floresta, 50(1), 971-982. https://doi.org/10.5380/ rf.v50i1.60023

Garcia-Gutierrez, J., Gonzalez-Ferreiro, E., Riquelme-Santos, J. C., Miranda, D., Dieguez-Aranda, U., \& Navarro-Cerrillo, R. M. (2014). Evolutionary feature selection to estimate forest stand variables using LiDAR. International Journal of Applied Earth Observation and Geoinformation, 26(1), 119-131. https://doi.org/10.1016/j.jag.2013.06.005

Guerra-Hernández, J., Cosenza, D. N., Cardil, A., Silva, C. A., Botequim, B., Soares, P., Silva, M., González-Ferreiro, E., \& Díaz-Varela, R. A. (2019). Predicting growing stock volume of eucalyptus plantations using 3-D point clouds derived from UAV imagery and ALS data. Forests, 10(10), 1-18. https://doi.org/10.3390/f10100905

Guerra-Hernández, J., Görgens, E. B., García-Gutiérrez, J., Rodriguez, L. C. E., Tomé, M., \& González-Ferreiro, E. (2016). Comparison of ALS based models for estimating aboveground biomass in three types of Mediterranean forest. European Journal of Remote Sensing, 49, 185-204. https://doi.org/10.5721/EuJRS 20164911

Haupt, R. L., \& Haupt, S. E. (2004). Practical genetic algorithms. Advances in Evolutionary Algorithms. Studies in Computational Intelligence (Vol. 18). Springer, Berlin, Heidelberg. https://doi.org/10.1007/11543138_2

He, C., Hong, X., Liu, K., Zhang, S., \& Wang, Q. (2016). An improved technique for non-destructive measurement of the stem volume of standing wood. Southern Forests, 78(1), 53-60. https://doi.org/10.2989/ 20702620.2015.1108617

Hess, A. F., Atanazio, K. A., Borsoi, G. A., Schorr, L. P. B., Souza, I. de A., Costa, E. A., ... Rosa, G. T. (2019). Crown efficiency and pine cones production for brazilian pine (Araucaria angustifolia (Bertol.) Kuntze) in south Brazil. Journal of Agricultural Science, 11(6), 247-259. https://doi.org/10.5539/jas.v11n6p247

Hess, A. F., Calgarotto, A. R., Pinheiro, R., \& Wanginiak, T. C. R. (2010). Proposta de manejo de Araucaria angustifolia utilizando o quociente de Liocourt e análise de incremento, em propriedade rural no Município de Lages, SC. Pesquisa Florestal Brasileira, 30(64), 337-345. https://doi.org/10.4336/2010.pfb.30.64.337

Hess, A. F., Loiola, T., Souza, I. de A., Minatti, M., Ricken, P., \& Borsoi, G. A. (2018a). Forest management for the conservation of Araucaria angustifolia in southern brazil. Floresta, 48(3), 373-382. https://doi.org/ 10.5380/rf.v48 i3.55452

Hess, A. F., Minatti, M., Costa, E. A., Schorr, L. P. B., da Rosa, G. T., de Arruda Souza, I., ... Abatti, R. (2020). Height-to-diameter ratios with temporal and dendro/morphometric variables for Brazilian pine in south Brazil. Journal of Forestry Research, 32, 191-202. https://doi.org/10.1007/s11676-019-01084-8

Hess, A. F., Silveira, A. C. da, Krefta, S. M., Santos, D. V. dos, Filho, M. D. H. V., Atanazio, K. A., ... Liesenberg, V. (2018b). Crown dynamics of Brazilian pine (Araucaria angustifolia) in Santa Catarina region of Brazil. 
Australian Journal of Crop Science, 12(03), 449-457. https://doi.org/10.21475/ajcs.18.12.03.pne928

Hueck, K. (1972). As florestas da América do Sul. Brasília, DF: Ed. da UnB. São Paulo, SP: Polígono.

IUCN. (2021). IUCN red list of threatened species. Retrieved December 27, 2021, from http://www. iucnredlist.org

Kapanoglu, M., Koc, I. O., \& Erdogmus, S. (2007). Genetic algorithms in parameter estimation for nonlinear regression models: An experimental approach. Journal of Statistical Computation and Simulation, 77(10), 851-867. https://doi.org/10.1080/10629360600688244

Li, Q., Kit Wong, F. K., \& Fung, T. (2019). Comparison Feature Selection Methods for Subtropical Vegetation Classification with Hyperspectral Data. International Geoscience and Remote Sensing Symposium, 3693-3696. https://doi.org/10.1109/IGARSS.2019.8898541

Li, Y., Wen, X. R., She, G. H., \& Lin, G. Z. (2017). Study on Poplar Crown Extraction and Correlation Based on UAV High Resolution Image. Forest Research, 30(4), 653-658. https://doi.org/10.13275/j.cnki.lykxyj. 2017.04.017

Marchi, M., Scotti, R., Rinaldini, G., \& Cantiani, P. (2020). Taper function for Pinus nigra in central Italy: Is a more complex computational system required? Forests, 11(4). https://doi.org/10.3390/F11040405

Martins, A. P. M., Debastiani, A. B., Pelissari, A. L., Machado, S. do A., \& Sanquetta, C. R. (2017). Estimativa do afilamento do fuste de araucária utilizando técnicas de inteligência artificial. Floresta e Ambiente, 24(0), 1-10. https://doi.org/10.1590/2179-8087.023416

Moreira, J., Serrano-Rosales, B., Valades-Pelayo, P. J., \& De Lasa, H. (2013). Determination of kinetic parameter in a unified kinetic model for the photodegradation of phenol by using nonlinear regression and the genetic algorithm. International Journal of Chemical Reactor Engineering, 11(2), 641-656. https://doi.org/10.1515/ijcre-2012-0003

Narvaes, I. S., Brena, D. A., \& Longhi, S. J. (2005). Estrutura da regeneração natural em floresta ombrófila mista na Floresta Nacional de São Francisco de Paula, RS. Ciência Florestal, 15, 331-342. https://doi.org/10.5902/198050981871

Özçelik, R., Diamantopoulou, M. J., Brooks, J. R., \& Wiant, H. V. (2010). Estimating tree bole volume using artificial neural network models for four species in Turkey. Journal of Environmental Management, 91(3), 742-753. https://doi.org/10.1016/j.jenvman.2009.10.002

Packalén, P., Temesgen, H., \& Maltamo, M. (2012). Variable selection strategies for nearest neighbor imputation methods used in remote sensing based forest inventory. Canadian Journal of Remote Sensing, 38(5), 557-569. https://doi.org/10.5589/m12-046

Paul, K. I., \& Roxburgh, S. H. (2020). Predicting carbon sequestration of woody biomass following land restoration. Forest Ecology and Management, 460, 117838. https://doi.org/10.1016/j.foreco.2019.117838

Pham, T. D., Yokoya, N., Xia, J., Ha, N. T., Le, N. N., Nguyen, T. T. T., ... Takeuchi, W. (2020). Comparison of machine learning methods for estimating mangrove above-ground biomass using multiple source remote sensing data in the red river delta biosphere reserve, Vietnam. Remote Sensing, 12(8), 1-24. https://doi.org/ $10.3390 / \mathrm{RS} 12081334$

Pohjankukka, J., Tuominen, S., Pitkänen, J., Pahikkala, T., \& Heikkonen, J. (2018). Comparison of estimators and feature selection procedures in forest inventory based on airborne laser scanning and digital aerial imagery. Scandinavian Journal of Forest Research, 33(7), 681-694. https://doi.org/10.1080/02827581. 2018.1482955

Puliti, S., Breidenbach, J., \& Astrup, R. (2020). Estimation of forest growing stock volume with UAV laser scanning data: Can it be done without field data? Remote Sensing, 12(8). https://doi.org/10.3390/ RS12081245

Puliti, S., Ørka, H. O., Gobakken, T., \& Næsset, E. (2015). Inventory of small forest areas using an unmanned aerial system. Remote Sensing, 7(8), 9632-9654. https://doi.org/10.3390/rs70809632

Rodrigues, A. L. (2016). Dinâmica demográfica, crescimento e simulações de manejo em remanescente de Floresta Ombrófila Mista. Universidade Federal do Paraná.

Rodriguez, F., Lizarralde, I., Fernández-Landa, A., \& Condés, S. (2014). Non-destructive measurement techniques for taper equation development: A study case in the spanish northern iberian range. European 
Journal of Forest Research, 133(2), 213-223. https://doi.org/10.1007/s10342-013-0739-5

Roush, W. B., \& Branton, S. L. (2005). A comparison of fitting growth models with a genetic algorithm and nonlinear regression. Poultry Science, 84(3), 494-502. https://doi.org/10.1093/ps/84.3.494

Sessions, J., Bettinger, P., \& Murphy, G. (2007). Heuristics in forest planning. In A. Weintraub, C. Romero, T. Bjørndal, R. Epstein, \& J. Miranda (Eds.), Handbook of operations research in natural resources (pp. 431-448). Springer. https://doi.org/10.1007/978-0-387-71815-6_23

Tiryana, T., Khasanah, L., Priyanto, Rahaju, S., \& Muhdin (2021). Form factors and volume models for estimating tree bole volume of mahogany at community forests in central Java. Indonesian Journal of Forestry Research, 8(2), 199-211. https://doi.org/10.20886/ijfr.2021.8.2.199-211

Tuominen, S., \& Haapanen, R. (2013). Estimation of forest biomass by means of genetic algorithm-based optimization of airborne laser scanning and digital aerial photograph features. Silva Fennica, 47(1), 1-20. https://doi.org/10.14214/sf.902

Zeng, H., Pukkala, T., \& Peltola, H. (2007). The use of heuristic optimization in risk management of wind damage in forest planning. Forest Ecology and Management, 24l(1-3), 189-199. https://doi.org/ 10.1016/j.foreco.2007.01.016

\section{Appendix A}

Estimate and significance of the coefficients fitted through nonlinear regression equations

\begin{tabular}{|c|c|c|c|c|c|c|}
\hline Type & Models & Coefficients & Estimate & Std. Error & t value & $\operatorname{Pr}(>|t|)$ \\
\hline \multirow{13}{*}{ NLS } & \multirow{2}{*}{$\mathrm{i}$} & $\mathrm{b}_{0}$ & 0.000164 & $1.654 \mathrm{E}-05$ & 9.90 & $<0.0001$ \\
\hline & & $b_{1}$ & 2.3835 & $2.460 \mathrm{E}-02$ & 96.90 & $<0.0001$ \\
\hline & \multirow{3}{*}{ ii } & $\mathrm{b}_{0}$ & 0.000053 & $5.237 \mathrm{E}-06$ & 10.06 & $<0.0001$ \\
\hline & & $\mathrm{b}_{1}$ & 2.1290 & $2.181 \mathrm{E}-02$ & 97.62 & $<0.0001$ \\
\hline & & $b_{2}$ & 0.7267 & 4.146E-02 & 17.52 & $<0.0001$ \\
\hline & \multirow{4}{*}{ iii } & $\mathrm{b}_{0}$ & 0.000075 & $2.732 \mathrm{E}-06$ & 27.63 & $<0.0001$ \\
\hline & & $b_{1}$ & 2.1400 & $7.628 \mathrm{E}-03$ & 280.55 & $<0.0001$ \\
\hline & & $\mathrm{b}_{2}$ & 0.8114 & $1.497 \mathrm{E}-02$ & 54.20 & $<0.0001$ \\
\hline & & $b_{3}$ & -0.2042 & 4.467E-03 & -45.71 & $<0.0001$ \\
\hline & \multirow{2}{*}{ iv } & $\mathrm{b}_{0}$ & 24.1732 & 0.4747 & 50.92 & $<0.0001$ \\
\hline & & $\mathrm{b}_{1}$ & 12.3517 & 0.6570 & 18.80 & $<0.0001$ \\
\hline & \multirow{2}{*}{$\mathrm{v}$} & $\mathrm{b}_{0}$ & 69.9343 & 13.8788 & 5.04 & $<0.0001$ \\
\hline & & $b_{1}$ & -0.2583 & 0.0572 & -4.52 & $<0.0001$ \\
\hline
\end{tabular}

\section{Appendix B}

\section{Comparison between volume equations ( $i$, ii and iii) fitted through nonlinear regression}

\begin{tabular}{llllllll}
\hline Type & Comparisons & Res.Df & Res.Sum Sq & Df & Sum Sq & F value & $\operatorname{Pr}(>$ F $)$ \\
\hline \multirow{4}{*}{ NLS } & i & 306 & 9.7876 & & & & \\
& ii & 305 & 4.7945 & 1 & 4.9931 & 317.6 & $<0.0001$ \\
& i & 306 & 9.7876 & & & & \\
& iii & 304 & 0.5951 & 2 & 9.1925 & 2348.0 & $<0.0001$ \\
& ii & 305 & 4.7945 & & & & \\
& iii & 304 & 0.5951 & 1 & 4.1995 & 2145.3 & $<0.0001$ \\
\hline
\end{tabular}

\section{Copyrights}

Copyright for this article is retained by the author(s), with first publication rights granted to the journal.

This is an open-access article distributed under the terms and conditions of the Creative Commons Attribution license (http://creativecommons.org/licenses/by/4.0/). 